\title{
Stem/progenitor cell marker expression in clear cell renal cell carcinoma: a potential relationship with the immune microenvironment to be explored
}

\author{
Ju-Yoon Yoon ${ }^{1 *}$, Craig Gedye ${ }^{2}$, Joshua Paterson ${ }^{3}$ and Laurie Ailles ${ }^{3}$
}

\begin{abstract}
Background: Clear cell renal cell carcinoma (ccRCC) is a markedly heterogeneous disease in many aspects, including the tumour microenvironment. Our previous study showed the importance of the tumour microenvironment in $\mathrm{ccRCC}$ xeno-transplant success rates. In order to better understand the potential relationship between TICS and the immune microenvironment, we employed a multi-modal approach, examining RNA and protein expression (flow cytometry, immunohistochemistry).

Methods: We first examined the gene expression pattern of 18 stem/progenitor marker genes in the cancer genome atlas (TCGA) ccRCC cohort. Flow cytometry was next employed to examine lineage-specific expression levels of stem/progenitor markers and immune population makeup in six, disaggregated, primary ccRCC specimens. Immunohistochemistry was performed on a commercial cCRCC tissue microarray (TMA).

Results: The 18 genes differed with respect to their correlation patterns with one another and to their prognostic significance. By flow cytometry, correlating expression frequency of $12 \mathrm{stem} /$ progenitor markers and CD10 resulted in two clusters-one with CD10 (marker of proximal tubular differentiation), and second cluster containing mostly mesenchymal stem cell (MSC) markers, including CD146. In turn, these clusters differed with respect to their correlation with different $\mathrm{CD}_{4} 5^{+}$lineage markers and their expression of immune checkpoint pathway proteins. To confirm these findings, four stem/progenitor marker expression patterns were compared with CD4, CD8 and CD20 in a cCRCC TMA which showed a number of similar trends with respect to frequency of the different tumourinfiltrating leukocytes.
\end{abstract}

Conclusion: Taken together, we observed heterogeneous but patterned expression levels of different stem/ progenitor markers. Our results suggest a non-random relationship between their expression patterns with the immune microenvironment populations in cCRCC.

Keywords: Clear cell renal cell carcinoma, Stem/progenitor cell, Tumour immune microenvironment, Immunohistochemistry, Tumour microenvironment

\footnotetext{
*Correspondence: juyoon@gmail.com

'Department of Laboratory Medicine and Pathobiology, University of Toronto, 27 King's College Circle, Toronto, Ontario M5S 1A1, Canada

Full list of author information is available at the end of the article
}

(c) The Author(s). 2020 Open Access This article is licensed under a Creative Commons Attribution 4.0 International License, which permits use, sharing, adaptation, distribution and reproduction in any medium or format, as long as you give appropriate credit to the original author(s) and the source, provide a link to the Creative Commons licence, and indicate if changes were made. The images or other third party material in this article are included in the article's Creative Commons licence, unless indicated otherwise in a credit line to the material. If material is not included in the article's Creative Commons licence and your intended use is not permitted by statutory regulation or exceeds the permitted use, you will need to obtain permission directly from the copyright holder. To view a copy of this licence, visit http://creativecommons.org/licenses/by/4.0/ The Creative Commons Public Domain Dedication waiver (http://creativecommons.org/publicdomain/zero/1.0/) applies to the data made available in this article, unless otherwise stated in a credit line to the data. 


\section{Background}

Renal cell carcinoma (RCC) is a heterogeneous group of carcinomas, of which clear cell carcinoma (ccRCC) comprises over $70 \%$ [1]. ccRCC is established to arise from the proximal tubules, and it is marked by frequent expression of CD10, a proximal tubule marker, normally expressed on the brush border of renal tubular epithelial cells $[2,3]$. In the kidney, a number of stem/progenitor cells have been identified; these stem/progenitor cells include the multipotent, often perivascular mesenchymal stem cells (MSCs), as well as tubular progenitor cells that appear to be involved in repair of nephrons after renal damage [4-8]. A number of different methods have been employed to isolate these cells, isolating the label-retaining cells, side population cells, as well as sorting by expression of different surface markers [8]. Similarly, stem-like cells (variously labelled cancer stem cells, tumour-initiating cells) have also been isolated from ccRCC specimens using a variety of different surface markers, including CD44, Ecto-5'-nucleotidase (CD73), CXCR4, CD105 and aldehyde dehydrogenase 1 (ALDH1) [9-13]. In turn, expression of these stem/progenitor markers has been associated with generally worse overall survival $[14,15]$.

Identification of tumour-initiating cells (TICs) may involve functional testing by xenotransplantation limiting dilution assay (LDA). Previously, our group had shown that the microenvironment plays a crucial role in ccRCC xenograft success rates [16]. Using the standard LDA, TICs are calculated to comprise on average 1 in 2 million, and the success rate was greatly enhanced by engrafting small tumour fragments, rather than purified putative TICs. Using this method, as few as 300 cells were sufficient for xenograft success, highlighting the important role for microenvironmental supplementation. While adding back the $\mathrm{CD} 45^{+}$cells alone was insufficient to increase engraftment success, the $\mathrm{CD} 45^{+}$cells comprised the predominant proportion of viable cells in engrafted tumour specimens.

In patients, the tumour microenvironment (TME) is an important prognostic factor in ccRCC. While greater tumour infiltration by $\mathrm{CD}^{+}$leukocytes has been associated with better prognosis in a number of cancers [17], ccRCC appears to be an exception, as higher $\mathrm{CD}^{+}$infiltration is associated with higher grade and worse survival $[18,19]$. Extensive $\mathrm{CD}^{+}$T-cell infiltration, however, comes in different patterns. The tumourinfiltrating lymphocytes (TILs) are found often in forms of cytotoxic T-cells, the activation of which is controlled by coordinated actions of the T-cell receptor (TCR) and the second, co-stimulatory signal via CD28-CD80/86 [20]. Actions of the infiltrating T-cells are dampened by the engagement of various immune checkpoint pathways, including competition of CTLA-4 (CD152) with
CD80/86 and the different B7 family members, including PD-L1 (CD274) $[20,21]$. When the $\mathrm{CD}^{+} \mathrm{T}$-cell infiltration is accompanied by low expression of immune checkpoints, extensive tumour infiltration was associated with better prognosis [19]. Similarly, expression of PD-1 by the TILs or expression of PD-L1 by the tumour cells are both associated with worse prognosis in ccRCC [22, 23]. In turn, immunotherapy in forms of PD-1/PD-L1 inhibition appears to be useful in ccRCC management, and monoclonal antibodies targeting PD-1/PD-L1 may be combined with tyrosine kinase inhibitors (TKIs) and CTLA4 inhibitors $[24,25]$.

The prognostic role of the TME is likely to be even more granular-in a recent study of the ccRCC immune microenvironment we identified 17 tumour-associated macrophage phenotypes and $22 \mathrm{~T}$-cell phenotypes [26], where a distinct immune composition correlated with patient survival. Multiple factors are likely playing different roles in shaping the immune TME in ccRCC. Examining gene expression and protein expression, we confirmed heterogeneous phenotypic resemblance to different stem/progenitor cells. In turn, these patterns correlated with different makeup of immune TME, as well as expression patterns of immune checkpoint proteins.

\section{Methods}

\section{Flow cytometry}

Six ccRCC specimens were obtained from the University Health Network (UHN) Program in Biospecimen Sciences from consenting patients in accordance with the policies of the UHN Research Ethics Board (REB ID\# 09-0828). Flow cytometry was performed as previously described [27]. Briefly, primary ccRCC specimens were disaggregated into single cell suspensions using collagenase treatment. The specimens were stained using CD45-APC-Cy7 (1:200), CD31-PE-Cy7 (1:200), CD34PerCP-Cy5.5 (1:50) (all BioLegend) and $1.2 \mathrm{mg} / \mathrm{ml}$ TE7biotin (in-house production from hybridoma obtained from ATCC) followed by Streptavidin-eFluor450 (1:400; eBioscience). These cells were then stained as described in Gedye et al. with an antibody panel that included other stem/progenitor and immune markers [27]. Data collection was performed on a Becton-Dickinson LSR II flow cytometer.

\section{Tissue microarray and immunohistochemistry}

Commercially available tissue microarrays (TMAs) were purchased from US BioMax (HKid-CRCC060PG-01 specs), which contains 60 human cores (30 ccRCC and 30 matched normal kidney). Immunohistochemistry (IHC) conditions for the four stem/progenitor markers are summarized in Table 1, including the pre-treatment conditions. Immunohistochemistry was performed using the standard streptavidin-biotin complex technique, after 
Table 1 Immunohistochemistry conditions

\begin{tabular}{|c|c|c|c|c|}
\hline Target & Antibody (Catalogue) & Pre-treatment & Dilution & Incubation \\
\hline CD44 & AbCam (ab157107) & no pretreatment & $1 / 500$ & $1 \mathrm{~h}$ \\
\hline CD90 & AbCam (133350) & Citrate $\mathrm{pH} 6.0$ & $1 / 300$ & $1 \mathrm{~h}$ \\
\hline CD146 (MCAM) & AbCam (75769) & Tris-EDTA pH 9.0 & $1 / 800$ & $1 \mathrm{~h}$ \\
\hline ST3GAL2 & Novus (NBPI87044) & Citrate $\mathrm{pH} 6.0$ & $1 / 100$ & Overnight \\
\hline
\end{tabular}

microwave antigen retrieval on $4-\mu \mathrm{m}$ sections of formalin-fixed, paraffin wax-embedded tissue.

For the four stem/progenitor markers, weak intra-lesional staining involving $<1 / 3$ of the carcinoma cells was scored as "+". " +++" score was reserved for moderate to strong staining of $>2 / 3$ of the lesional cells. "++" cores included those with diffuse $(>2 / 3)$, weak staining, and those with moderate to strong staining limited to $<1 / 3$ of carcinoma cells. For the immune markers, only strong, membranous staining of CD4, CD8 and CD20 in small round cells were scored as positive staining, and the numbers of stained cells were counted for each core. Any intra-vascular cells or haemorrhagic areas were excluded from the counting.

\section{Clustering of mRNA levels and flow cytometry results and statistics}

The expression levels of stem/progenitor marker genes and immune infiltrate-related genes were downloaded from cBioPortal (http://www.cbioportal.org/), restricted to RNA Seq V2 RSEM z-score values. The data downloaded were limited to the cases published in the 2013 TCGA study, comprised of 417 cases examined by RNA Seq (V2 RSEM) [28]. Unsupervised clustering of mRNA expression and IHC staining patterns were performed using Cluster 3.0, an opensource clustering software, and visualized using TreeView [29].

All statistics were performed using JMP14 (IBM SAS). Comparisons of non-parametric variables (ex. IHC intensity between groups/clusters) were performed using ANOVA. Correlations between two continuous variables were performed using Pearson correlation. Survival analyses were performed using the Kaplan-Meier method.

\section{Results}

mRNA expression patterns in the TCGA ccRCC cohort

We examined the expression levels of 18 stem/progenitor marker genes, along with $M M E$, a marker of mature proximal tubular cells (encoding CD10), in the TCGA ccRCC cohort. Gene expression patterns were heterogeneous in the ccRCC cohort. Examining for correlations between the 19 genes by unsupervised clustering, two distinct clusters were formed (Fig. 1a). The smaller cluster included CD9, SOX2, MSI2 and PROM1 (CD133), along with $M M E$ (CD10), the marker of mature proximal tubular epithelium. The remaining 14 stem/ progenitor marker genes clustered with one another, with particularly strong correlations seen between a number of mesenchymal stem cell (MSC) markers, including MCAM (CD146), PDGFRB (CD140B), and THY1 (CD90), with ST3GAL2, the rate-limiting enzyme involved in SSEA-3 conversion to SSEA-4.

In the TCGA cohort, these 19 genes were also heterogeneous with respect to their prognostic significance. Among them, $C D 44$ was the only gene where higher expression was associated with worse overall survival (i.e. higher risk ratio) when the mRNA Z-score was examined as a continuous variable (risk ratio $=1.37, p=$ 0.0005). CD44 expression correlated negatively with $M M E$ (Pearson correlation coefficient $(\mathrm{PCC})=0.1242$, $p=0.0091$ ), suggesting that higher CD44 mRNA may be associated with either more primitive and/or dedifferentiated carcinomas.

Considering the role for microenvironmental supplementation in tumour xenograft success, we next examined the relationship between the expression levels of the different stem/progenitor marker genes and a set of immune microenvironment-related genes, including a number of T- $(C D 2, C D 5, C D 7, C D 4, C D 8 A)$, B-cell markers (CD19, MS4A1, CD79A, CD79B), as well as a number of immune checkpoint pathway genes (CD28, CD80, CD86, CD274 (PD-L1), PDCD1LG2 (PD-L2), PDCD1 (PD1), ICOSLG, ICOS, CD274 and LAG3) (Supp. Figure 1). Examining for correlations, CD44 and CXCR4 showed particularly strong positive correlations with most of the immune genes examined. CD276 (B7-H3) expression correlated positively with a number of MSC markers and ST3GAL2. While CD276 is frequently expressed on tumour endothelium, CD276 expression has been reported in some tumour cell subsets [30].

While these correlations between stem/progenitor marker gene expression and immune environment makeup, several genes examined, especially CD44 and CXCR4, are expressed by non-tumoural cells. Indeed, CD44 is expressed by most $\mathrm{CD} 45^{+}$cells, and, as expected, CD44 expression correlated positively with PTPRC $(\mathrm{CD} 45)(\mathrm{PCC}=0.2690, p<0.0001)$.

Lineage-specific surface marker expression assessment by flow cytometry

Because the above correlations were performed agnostic to lineage specificity (ex. immune vs. carcinoma cells) 


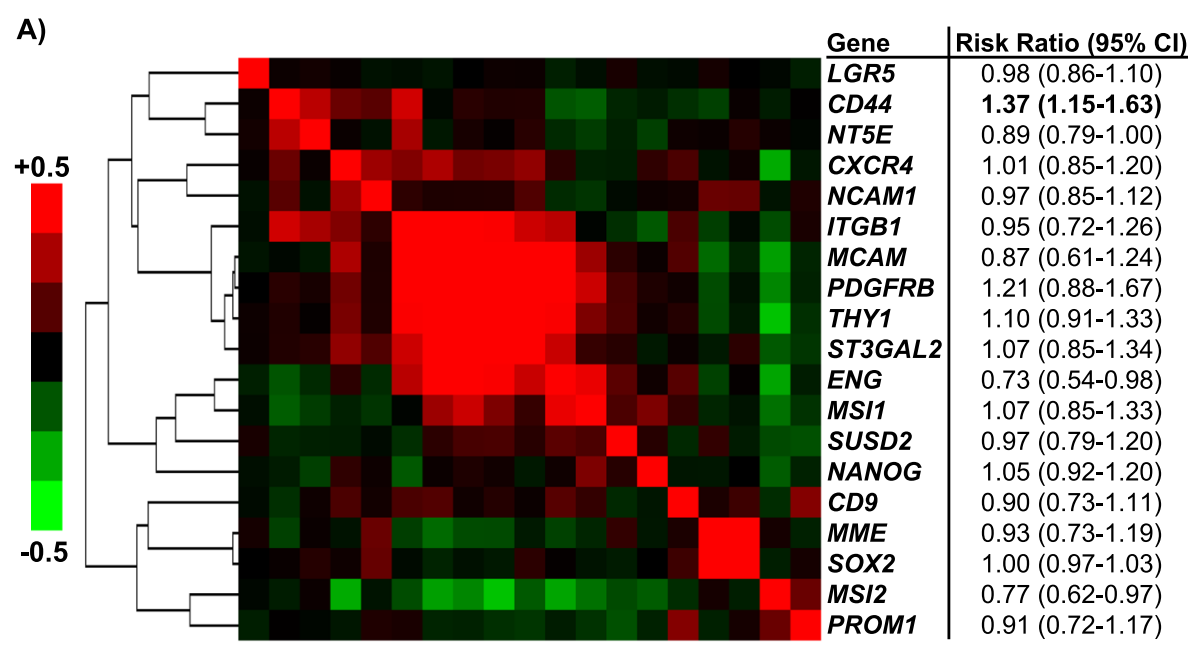

B)

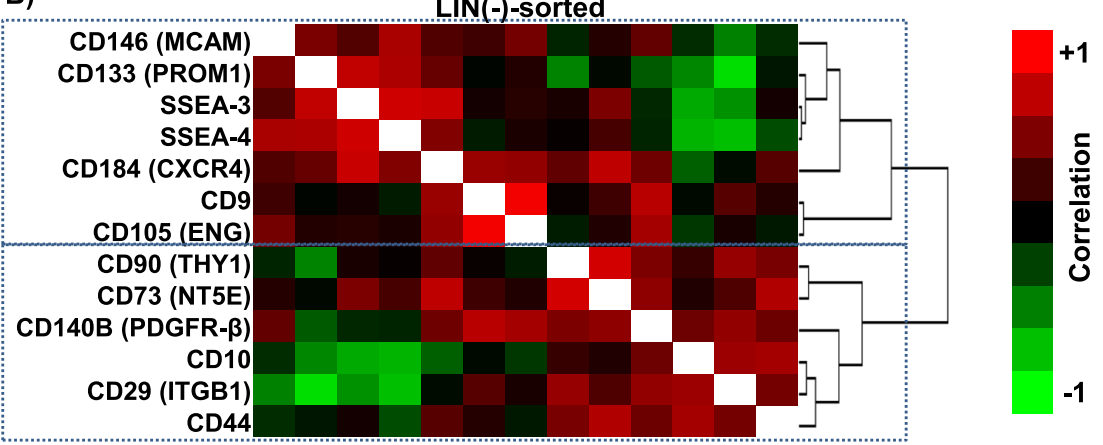

Fig. 1 Correlation patterns between the stem/progenitor markers in ccRCC. a Clustered correlation, showing the correlation coefficients between mRNA for the different stem/progenitor cell marker genes along with MME (encoding CD10), a marker of mature renal tubular cells from the TCGA data. The risk ratios correspond to their impact on the overall survival, examining the gene expression levels (Z-scores) as continuous variables. b Clustered correlation heatmap displaying the Pearson correlations between the $12 \mathrm{stem} /$ progenitor cell markers and CD10 in the LIN(-) population

and overlapping expression by different lineages (esp. CD44 and CXCR4), we next disaggregated primary ccRCC specimens and examined surface expression by flow cytometry. By co-staining with anti-CD45, CD34 and TE7 antibodies [31], we were able to label the different subpopulations as leukocytes $\left(\mathrm{CD} 45^{+}\right)$, endothelial cells $\left(\mathrm{CD} 34^{+}\right)$, fibroblasts $\left(\mathrm{TE} 7^{+}\right)$and lineage (LIN)-negative cells (i.e. carcinoma cells). Among the 18 stem/progenitor genes examined by mRNA, we examined 12 surface markers, namely CD9, CD29, CD44, CD73, CD90, CD105 (Endoglin), CD133, CD140B, CD146, CD184 (CXCR4), SSEA-3 and SSEA-4, along with CD10. Unsupervised clustering of the 13 surface markers resulted in four discrete clusters that corresponded to labelled lineages (Supp. Figure 2). The 13 surface markers differed with respect to their ability to discriminate between the lineages. For example, CD29 (ITGB1) was expressed at high levels in all the sub-populations, while CD133 (PROM1) was rarely expressed. The LINnegative sub-population showed the highest frequency of CD10 expression. A number of MSC markers, including CD44, CD73, CD90, CD140B and CD146, were expressed at heterogeneous levels within the LINnegative sub-population, with higher expression in the fibroblast and endothelial sub-populations. Focusing on the LIN-negative cells, the expression pattern of the 13 surface markers resulted in two correlation clusters, with distinctively different pattern compared to the mRNAbased clusters; one CD10-containing cluster (with CD90, CD73, CD140B, CD29 and CD44), and another cluster containing CD146 (MCAM), along with CD133, SSEA-3, SSEA-4, CD9 and CXCR4 (Fig. 1b).

We next examined the different sub-populations and compared the expression levels of different immune population markers within the $\mathrm{CD} 45^{+}$population with respect to stem/progenitor marker expression in the LIN-negative population (Fig. 2a). Among the stem/progenitor markers, expression of CD10, CD29 and CD44 in the LIN-negative sub-population showed particularly strong positive correlation with higher proportion of $\mathrm{CD} 45^{+}$cells expressing a number of $\mathrm{T}$-cell surface markers (i.e. $\mathrm{CD} 3, \mathrm{CD} 5, \mathrm{CD} 7, \mathrm{CD} 8, \mathrm{TCR} \alpha / \beta$ ), suggesting 


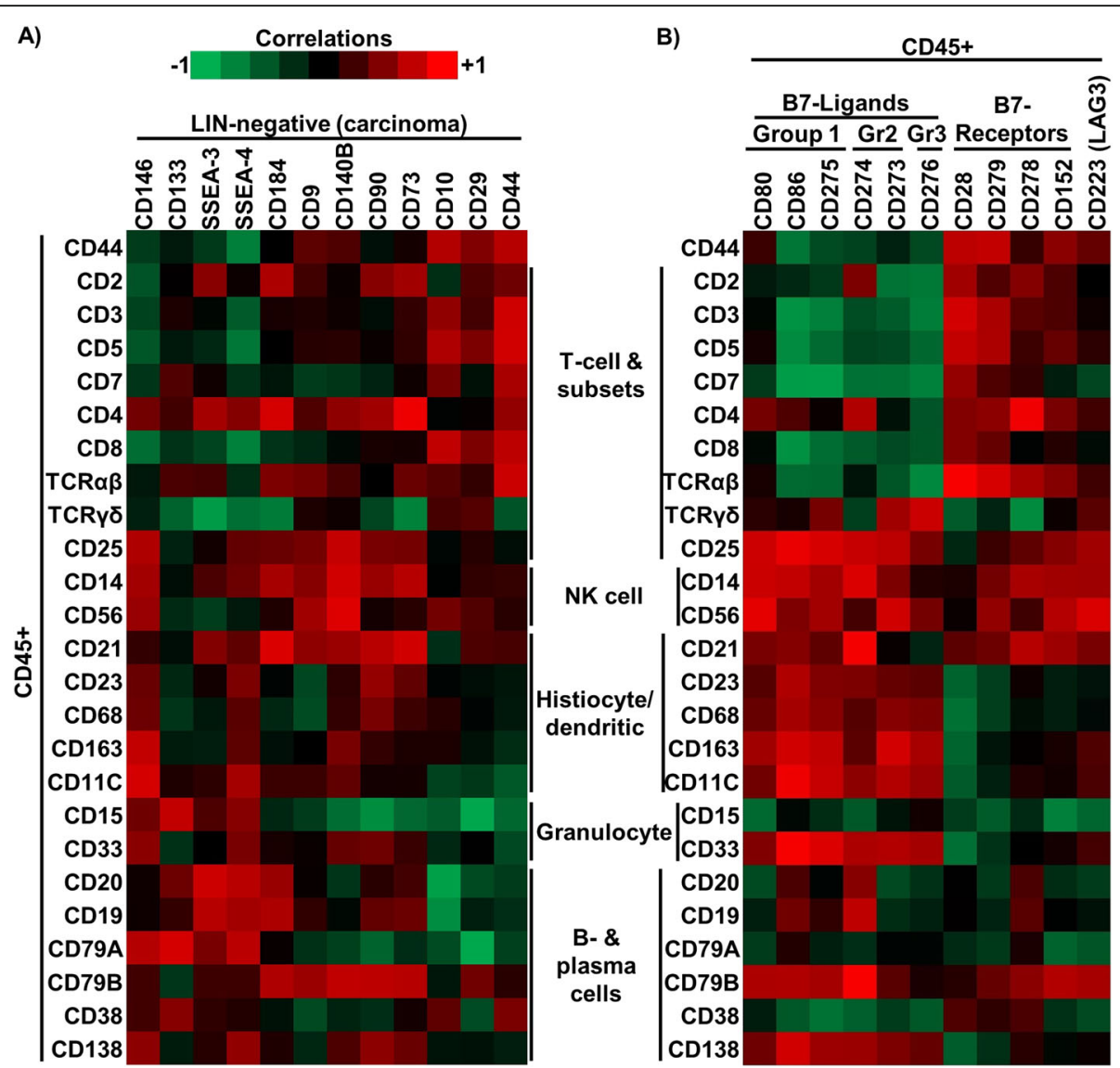

Fig. 2 Flow cytometric assessment of the immune microenvironment and its relationship with stem/progenitor marker expression. a Correlation heatmap displaying the Pearson correlations between the $13 \mathrm{stem} /$ progenitor cell marker expression levels on the LIN-cells compared to the different CD45+ subset markers. b Correlation heatmap displaying the Pearson correlations between the 11 immune checkpoint pathway proteins expression levels on the CD45+ cells compared to the different CD45+ subset markers

enrichment for cytotoxic CD8 ${ }^{+} \mathrm{T}$-cells. In contrast, correlation patterns with SSEA-3 and SSEA-4 suggested enrichment for B-cells (based on correlation with CD19, CD20, CD79A) and CD4 ${ }^{+}$cells.

Next we examined immune checkpoint proteins in the $\mathrm{CD} 45^{+}$sub-population (Fig. 2b). B7 family receptors, including CD28 and CD279 (PD-1), generally correlated positively with a number of T-cell markers (Fig. 2 b), likely reflecting the expression of the $\mathrm{B} 7$ family receptors by the tumour-infiltrating T-cells. On the other hand, expression of B7 family ligands, including the negative immune checkpoint regulators CD152 (CTLA4), CD274 (PD-L1) and CD273 (PD-L2), correlated positively with NK cell markers (CD14 and CD56), along with histiocytic/dendritic markers (CD21, CD23, CD68, CD163, CD11c), and CD25 (expressed Tregs, among others).

When we examined the expression patterns of the immune checkpoint proteins on different sub-populations, CD140B and CD90 positivity in the LIN-negative subpopulation showed generally positive correlation with the expression of most of the immune checkpoint proteins examined (Fig. 3). These correlations were seen across the different sub-populations, including endothelial cells and fibroblasts. On the other hand, CD133, SSEA/3 and SSEA-4 correlated negatively with most of the immune checkpoint proteins examined, and these correlations were more striking in the $\mathrm{CD}_{4} 5^{+}$and $\mathrm{CD}_{4} 4^{+}$sub-populations. Taken together, these correlation patterns point to a novel relationship between the immune microenvironment with different patterns of stem/progenitor marker expression by carcinoma cells.

\section{Immunohistochemical examination of stem/progenitor} markers and the immune microenvironment

In order to confirm our flow cytometry-based observations, we examined four stem/progenitor markers (CD44, CD90, CD146, ST3GAL2) and three immune markers (CD4, CD8, CD20) by immunohistochemistry on tissue microarray (TMA) sections, comprised of 60 cores (30 ccRCCs and 30 matched normal kidney) (representative cores in Supp. Figure 3 and graphical summary in Fig. 4a). In the normal kidney cores, strong 


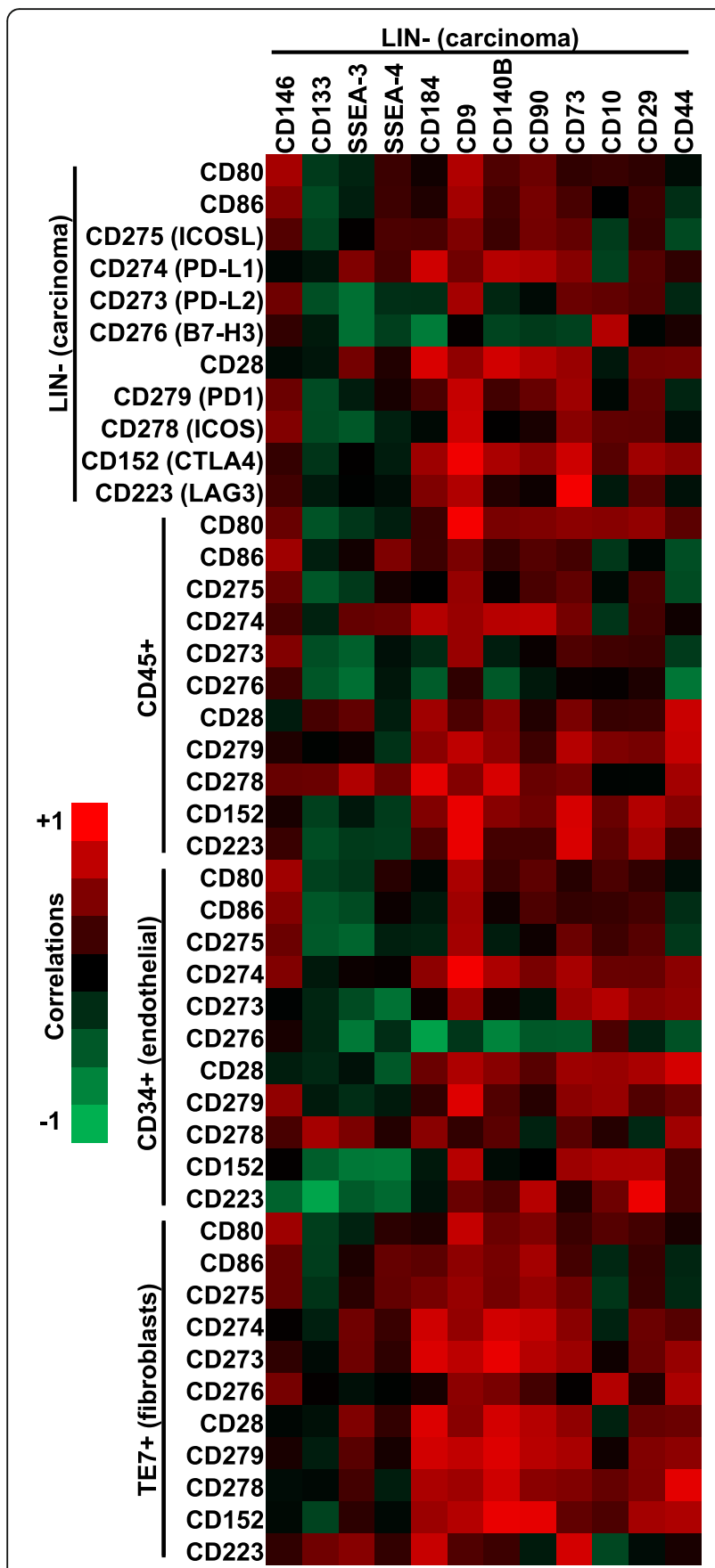

Fig. 3 Correlation heatmap displaying the Pearson correlations between the $13 \mathrm{stem} /$ progenitor cell marker expression levels on the LIN-cells compared to the different immune markers in the four sub-populations

CD146 staining is seen also in the vessel walls, including the glomerular arterioles. This vascular staining pattern is retained in most ccRCC cores, highlighting the delicate intra-tumoural vessels. Some cores showed membranous staining of individual and small groups of tumour cells (up to $2+$ staining) in 5/30 cases, and this pattern was interpreted as true lesional staining.
In the normal kidney cores, CD90 expression is seen in some vessel walls and the renal tubules, more predominantly in the proximal portions, with apical accentuation, likely corresponding to the brush borders (Supp. Figure 4). CD90 staining in vessel walls could be seen in rare cases. In ccRCC cases, CD90 staining is mostly in the vessel walls, with some larger cells being highlighted, perhaps representing fibroblasts. Membranous staining of the carcinoma cells, either as individual or small groups of cells was observed in a subset, with relatively diffuse staining seen in $8 / 30$ cases.

Patchy, cytoplasmic ST3GAL2 expression is seen in the non-tumoural glomeruli and the vessel walls. In ccRCC cases, 10/30 cases showed lesional, cytoplasmic ST3GAL2 staining. Negative cases showed weak staining in the vessel walls, without discernible lesional staining. CD44 expression in the normal kidney cores was seen in some vessel walls and small mononuclear cells, interpreted to represent leukocytes. Only weak CD44 expression was seen in $3 / 30(10 \%)$ of the tumours. For the other cores, CD44 stained a number of smaller, intralesional cells, interpreted to represent TILs, and negative in the actual tumour cells, with some vascular staining.

There was no clear pattern with respect to tumour grade and stem/progenitor marker staining; 22/30 cases were of nucleolar grade 2 , and most positively stained cases were of grade 2. Comparing the different stem/progenitor markers, the cores with stronger CD90 staining tended to show stronger CD146 staining (Fig. 4a). Otherwise, there were no clear patterns with respect to the relationship between the different markers.

We next examined the same TMA for frequency of $\mathrm{CD}^{+}, \mathrm{CD}^{+}$and $\mathrm{CD} 20^{+}$cells (Supp. Figure 4). The number of $\mathrm{CD}^{+}$cells was not significantly different based on the stem/progenitor marker expression, although the number of $\mathrm{CD}^{+}$cells tended to be lower in $\mathrm{CD} 146^{\mathrm{High}}$ and ST3GAL2 ${ }^{\mathrm{High}}$ cores, in line with the flow cytometry- and the mRNA-based observations (Fig. 4b). CD4 ${ }^{+}$cells were more frequent with ST3GAL2 ${ }^{\text {High }}$ cores (Wilcoxon $p=0.0282$ ). CD20 ${ }^{+}$cells also tended to be more frequent in $\mathrm{CD} 90^{\mathrm{High}}$ cores. While most comparisons did not reach statistical significance, the trends were similar to that seen with the flow cytometry data.

Taken together, our results confirm that the immune microenvironment in ccRCC is heterogeneous with respect to both its makeup and immune checkpoint protein expression. There is also striking heterogeneity in the expression patterns of different stem/progenitor markers. Correlations and clustering patterns seen between these features suggest a nonrandom relationship, the significance of which remains to be elucidated. 
A)

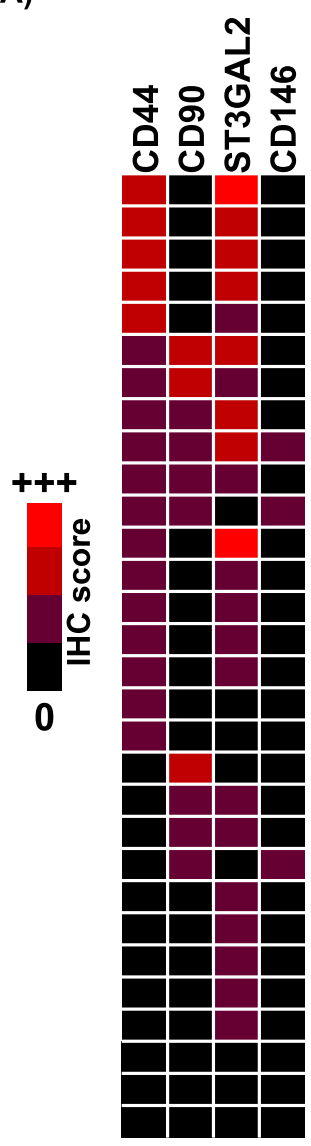

B)
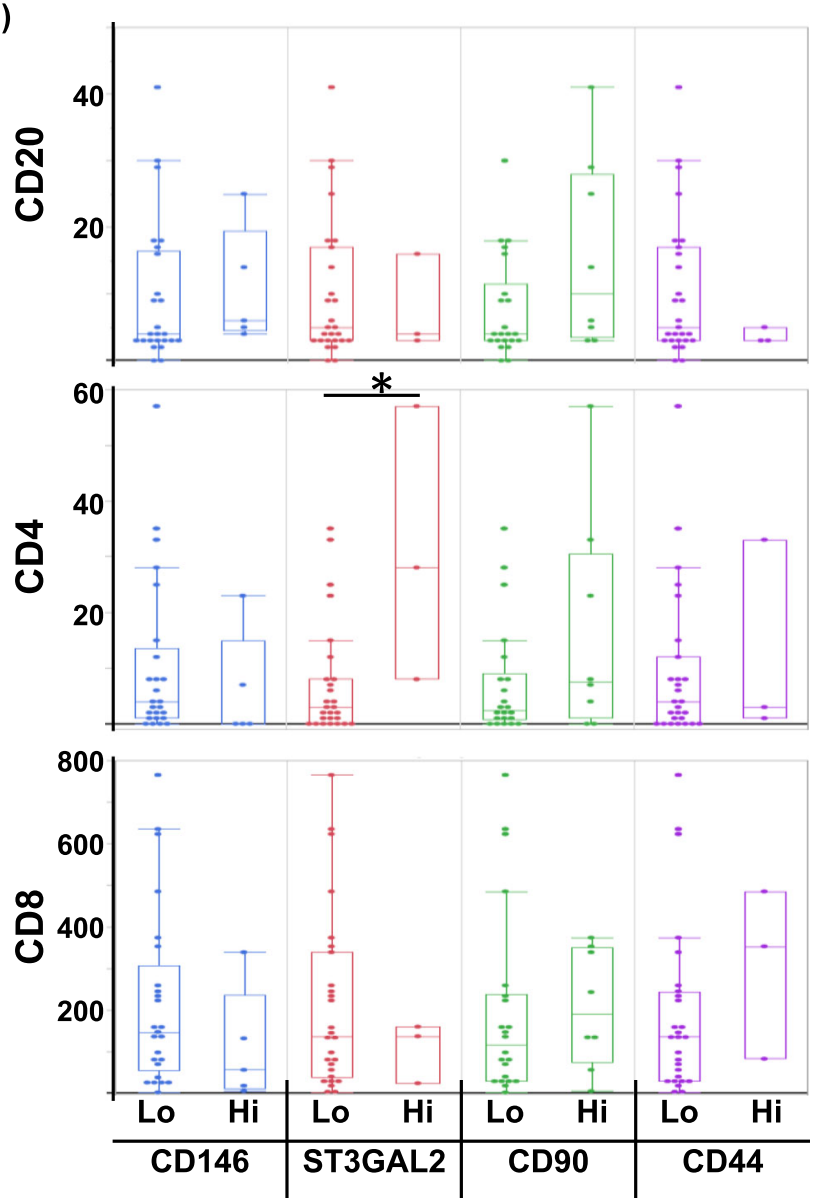

Fig. 4 Tissue microarray results. a Graphical summary of the IHC results from $30 \mathrm{ccRCC}$ cores, with the indicated staining intensity. b Frequency of the indicated immune infiltrate in cores with carcinomas expressing the indicated stem/progenitor marker proteins. ${ }^{*}$ indicates Wilcoxon test $p=0.0282$. Other unmarked comparisons were non-significant $(p>0.05)$

\section{Discussion}

Adult tissue regeneration is a dynamic, homeostatic process that engages a number of different stem/progenitor cells. This may also be true in cancer growth, where different subtypes of TICs, with heterogeneous surface marker profiles, may be engaged in cancer growth in patients and in cancer reconstitution in xenograft models. Examining the different possible stem/progenitor markers in ccRCC, we observed different patterns of correlation clusters. These patterns showed heterogeneity across different modalities utilized. Part of the discrepancy is related to their expression by different lineages (ex. CD44), an issue that was addressed by examining lineage-specific expression by flow cytometry. Flow cytometry also allowed for robust distinction between the different infiltrating leukocytes. However, distinction between true TILs and bystander leukocytes is perhaps best done by IHC, especially considering the rich vasculature and frequent haemorrhage that can be seen in ccRCC specimens. The clear drawback in IHC was encountered in assessing CD90 and
CD146 staining, where distinguishing between vascular and true lesional staining was difficult.

Despite these challenges, some of the patterns seen from the TMA IHC data showed similar trends seen with flow cytometry data, with both data sets pointing to a non-random relationship between stem/progenitor marker expression and the immune microenvironment makeup. A subset of stem/progenitor markers correlated positively with $\mathrm{CD}^{+}{ }^{+}$T-cell markers (ex. CD10, CD44), while others correlated positively with B-cell markers (ex. SSEA-3/SSEA-4). Interestingly, a different set of stem/ progenitor markers showed the strongest positive correlations with the different immune checkpoint inhibitor proteins (ex. CD140B), including CD274 (PD-L1). This is an interesting biological discordance that may have treatment implications in immune checkpoint therapy.

An interesting question is regarding the stem/progenitor cell marker expression significance. Expression of different stem/progenitor marker genes and proteins may be an acquired phenotype in the setting of epithelial-mesenchymal 
transition (EMT). ccRCC is a peculiar carcinoma, being one of the few carcinomas that normally express both cytokeratin and vimentin type intermediate filaments [32, 33], the latter being a well-established marker of mesenchymal differentiation [34]. When aberrantly expressed in carcinoma cells, vimentin is seen as a marker of EMT. However, electron microscopic features of ccRCC are that of carcinoma, with long microvilli on the apical surface and numerous cell junctions [35], with the microvilli being the highlighted by (apical) CD10 staining [2, 3]. Dedifferentiation, perhaps related to EMT, can be seen in ccRCC. This is seen in the form of sarcomatoid (de-)differentiation, marked by spindle cell histology, which may be accompanied by CD10 loss [36]. Increased CD44 expression has been associated with sarcomatoid differentiation and aberrant p53 expression in renal cell carcinoma [37-39]. Sarcomatoid differentiation has been shown to harbour significantly higher mutational burden [39], along with higher PD-1 and PD-L1 (CD274) expression [40]. Unfortunately, the number of tumours cores with sarcomatoid foci was too small for a meaningful comparison. Regardless, there lacked a clear relationship between tumour grade with TIL frequency and stem/progenitor marker expression patterns, suggesting that EMT is unlikely to be the main biological driver.

A number of stem/progenitor markers examined in this study have been used to isolate TICs/cancer stem cells in ccRCC and many other cancers. While tempting, higher expression of these markers cannot be equated with TIC enrichment. In particular, CD90 may be a particularly poor marker; CD90 staining pattern in the normal proximal tubules was reminiscent of that seen with CD10, raising the possibility that CD90 expression may simply be a retained phenotype. For others, while a number of MSC markers have been used to isolate TICs in many settings, quantifying TICs is best performed by functional assays, as we had previously performed [16]. Unfortunately, because these functional assays are generally performed in systems lacking a functional immune system, the impact of TICs on the immune microenvironment remains poorly understood. Could the other stem/progenitor marker expression be an intrinsic ( $v s$. acquired) feature in some carcinomas, related to their cell-of-origin? While ccRCC is generally well established to arise from the proximal tubules, a number of different stem/progenitor cells are well-capable of regenerating those structures and may serve as potential cells-oforigin for a subset of ccRCC. It is possible that a subset of ccRCCs may be more primitive than others, a feature not derived through dedifferentiation but rather related to their origin. While this question is outside of the scope of this study, the possibility is raised, in which case the carcinoma-immune microenvironment relationship may be a feature established early in tumourigenesis.
A number of interesting correlations have been uncovered in this study, but this study was limited to correlations. We were also limited by a much smaller sample size for flow cytometric analysis, thus limiting the power of some of the correlations observed. However, our results point to a novel, unexplored relationship between cancer pathogenesis and the immune microenvironment. Going forward, a more solid conclusion about the relationship between the nature of the TICs and the microenvironment may be attainable by serially following and comparing the tumour and microenvironment makeup.

\section{Conclusions}

The importance of the immune microenvironment in ccRCC is obvious, with respect to both prognosis and therapy. Understanding the marked heterogeneity in the immune microenvironment will be pivotal in choosing the right patients for immune checkpoint therapy. Tumour mutational burden and presentation of neo-antigens through the immunoproteasome pathway is one of the factors that shape the microenvironment; our data highlight immunophenotypic resemblance of ccRCC to different stem/progenitor cells as another potential factor. Further studies are required to verify this relationship and to understand its significance.

\section{Supplementary information}

Supplementary information accompanies this paper at https://doi.org/10. 1186/s12885-020-06733-4.

Additional file 1: Supp. Figure 1. Correlation heatmap displaying the Pearson correlations between the 19 stem/progenitor cell marker genes in the TCGA cohort vs. PTPRC and immune checkpoint inhibitor genes.

Additional file 2: Supp. Figure 2. Clustered expression heatmap, displaying the expression levels for 13 markers $(12$ stem/progenitor cell markers and CD10) in the six patient samples, in the four different cell populations as indicated.

Additional file 3: Supp. Figure 3. A) Representative immunostaining results from normal (left-most column) and ccRCC cores (centre and right-most columns). Bar $=100 \mu \mathrm{m}$.

Additional file 4: Supp. Figure 4. Representative immunostaining results for cores with high CD4, CD8 or CD20 counts. Bar $=100 \mu \mathrm{m}$.

\section{Abbreviations \\ ccRCC: Clear cell renal cell carcinoma; IHC: immunohistochemistry; \\ LDA: Limiting dilution assay; MSC: Mesenchymal stem cell; RCC: Renal cell carcinoma; TCR: T-cell receptor; TCGA: The cancer genome atlas; TMAs: Tissue microarrays; TICs: Tumour-initiating cells; TILs: Tumour-infiltrating lymphocytes; TME: tumour microenvironment}

\section{Acknowledgements}

Not Applicable.

\section{Authors'contributions}

J.Y. contributed to the design of the work, data interpretation, and manuscript writing. J.P. contributed to data acquisition (flow cytometry). C.G. contributed to data interpretation and manuscript writing. L.A. contributed to the design of the work, data interpretation, manuscript writing, and securing grant funding. All authors have read and approved the manuscript. 


\section{Funding}

L.A. is funded by the Ontario Institute for Cancer Research (IA-016) and the Princess Margaret Cancer Foundation. The funding bodies were not involved in design of the study and collection, analysis, interpretation of data, or in writing the manuscript.

\section{Availability of data and materials}

The datasets used and/or analysed during the current study are available from the corresponding author on reasonable request.

\section{Ethics approval and consent to participate}

The research was performed in accordance with the policies of the University Health Network (UHN) Research Ethics Board (Toronto, Ontario, Canada, REB ID\# 09-0828).

The primary patient specimens were collected as part of the UHN Program in Biospecimen Sciences from consenting patients. These biobanked specimens were obtained with broad consent and utilized in accordance with the banking consent

The TMA used was a commercially available set of tumours (BioMax).

\section{Consent for publication}

Not applicable.

\section{Competing interests}

The authors declare that they have no competing interests.

\section{Author details}

'Department of Laboratory Medicine and Pathobiology, University of Toronto, 27 King's College Circle, Toronto, Ontario M5S 1A1, Canada. ${ }^{2}$ Hunter Medical Research Institute, Newcastle, New South Wales, Australia. ${ }^{3}$ Department of Medical Biophysics, University of Toronto, Toronto, Ontario, Canada.

\section{Received: 14 November 2019 Accepted: 10 March 2020}

\section{Published online: 03 April 2020}

\section{References}

1. Moch $\mathrm{H}$, Humphrey PA, Ulbright TM, Reuter VE: WHO Classification of Tumours of the Urinary System and Male Genital Organs. 4th Edition, vol. 8; 2016.

2. Avery AK, Beckstead J, Renshaw AA, Corless CL. Use of antibodies to RCC and CD10 in the differential diagnosis of renal neoplasms. Am J Surg Pathol. 2000;24(2):203-10.

3. Van der Hauwaert C, Savary G, Gnemmi V, Glowacki F, Pottier N, Bouillez A, Maboudou P, Zini L, Leroy X, Cauffiez C, et al. Isolation and characterization of a primary proximal tubular epithelial cell model from human kidney by CD10/CD13 double labeling. PLoS One. 2013:8(6):e66750.

4. da Silva ML, Chagastelles PC, Nardi NB. Mesenchymal stem cells reside in virtually all post-natal organs and tissues. J Cell Sci. 2006;119(Pt 11):2204-13.

5. Oliver JA, Maarouf O, Cheema FH, Martens TP, Al-Awqati Q. The renal papilla is a niche for adult kidney stem cells. J Clin Invest. 2004;114(6):795-804.

6. Humphreys BD, Valerius MT, Kobayashi A, Mugford JW, Soeung S, Duffield JS, McMahon AP, Bonventre JV. Intrinsic epithelial cells repair the kidney after injury. Cell Stem Cell. 2008;2(3):284-91.

7. Hishikawa K, Takase O, Yoshikawa M, Tsujimura T, Nangaku M, Takato T. Adult stem-like cells in kidney. World J Stem Cells. 2015;7(2):490-4.

8. Suzuki E, Fujita D, Takahashi M, Oba S, Nishimatsu H. Adult stem cells as a tool for kidney regeneration. World J Nephrol. 2016;5(1):43-52.

9. Zagzag D, Krishnamachary B, Yee H, Okuyama H, Chiriboga L, Ali MA, Melamed J, Semenza GL. Stromal cell-derived factor-1alpha and CXCR4 expression in hemangioblastoma and clear cell-renal cell carcinoma: von Hippel-Lindau loss-of-function induces expression of a ligand and its receptor. Cancer Res. 2005;65(14):6178-88.

10. Song L, Ye W, Cui Y, Lu J, Zhang Y, Ding N, Hu W, Pei H, Yue Z, Zhou G. Ecto-5'-nucleotidase (CD73) is a biomarker for clear cell renal carcinoma stem-like cells. Oncotarget. 2017;8(19):31977-92.

11. Gassenmaier M, Chen D, Buchner A, Henkel L, Schiemann M, Mack B, Schendel DJ, Zimmermann W, Pohla H. CXC chemokine receptor 4 is essential for maintenance of renal cell carcinoma-initiating cells and predicts metastasis. Stem Cells. 2013;31(8):1467-76.
12. Bussolati B, Bruno S, Grange C, Ferrando U, Camussi G. Identification of a tumor-initiating stem cell population in human renal carcinomas. FASEB J. 2008;22(10):3696-705.

13. Ueda K, Ogasawara S, Akiba J, Nakayama M, Todoroki K, Sanada S, Suekane S, Noguchi M, Matsuoka K, Yano H. Aldehyde dehydrogenase 1 identifies cells with cancer stem cell-like properties in a human renal cell carcinoma cell line. PLoS One. 2013:8(10):e75463.

14. Zanjani LS, Madjd Z, Abolhasani M, Rasti A, Fodstad O, Andersson Y, Asgari M. Increased expression of CD44 is associated with more aggressive behavior in clear cell renal cell carcinoma. Biomark Med. 2018;12(1):45-61.

15. Cheng B, Yang G, Jiang R, Cheng Y, Yang H, Pei L, Qiu X. Cancer stem cell markers predict a poor prognosis in renal cell carcinoma: a meta-analysis. Oncotarget. 2016;7(40):65862-75.

16. Gedye C, Sirskyj D, Lobo NC, Meens J, Hyatt E, Robinette M, Fleshner N, Hamilton RJ, Kulkarni G, Zlotta A, et al. Cancer stem cells are underestimated by standard experimental methods in clear cell renal cell carcinoma. Sci Rep. 2016:6:25220.

17. Vesely MD, Kershaw MH, Schreiber RD, Smyth MJ. Natural innate and adaptive immunity to Cancer. Annu Rev Immunol. 2011;29(1):235-71.

18. Nakano O, Sato M, Naito Y, Suzuki K, Orikasa S, Aizawa M, Suzuki Y, Shintaku I, Nagura H, Ohtani H. Proliferative activity of Intratumoral CD8<sup $>+$ $</$ sup $>$ T-lymphocytes as a prognostic factor in human renal cell carcinoma. Clinicopathologic Demonstration Antitumor Immun. 2001;61(13): 5132-6.

19. Giraldo NA, Becht E, Pagès F, Skliris G, Verkarre V, Vano Y, Mejean A, SaintAubert N, Lacroix L, Natario I, et al. Orchestration and prognostic significance of immune checkpoints in the microenvironment of primary and metastatic renal cell Cancer. Clin Cancer Res. 2015;21(13):3031-40. https://doi.org/10.1158/1078-0432.

20. Durgeau A, Virk Y, Corgnac S, Mami-Chouaib F. Recent advances in targeting CD8 T-cell immunity for more effective Cancer immunotherapy. Front Immunol. 2018:9:14.

21. Pardoll DM. The blockade of immune checkpoints in cancer immunotherapy. Nat Rev Cancer. 2012;12(4):252

22. Thompson RH, Kuntz SM, Leibovich BC, Dong H, Lohse CM, Webster WS, Sengupta S, Frank I, Parker AS, Zincke H, et al. Tumor B7-H1 is associated with poor prognosis in renal cell carcinoma patients with long-term followup. Cancer Res. 2006;66(7):3381-5.

23. Thompson RH, Dong H, Lohse CM, Leibovich BC, Blute ML, Cheville JC, Kwon ED. PD-1 is expressed by tumor-infiltrating immune cells and is associated with poor outcome for patients with renal cell carcinoma. Clin Cancer Res. 2007;13(6):1757-61.

24. Santoni M, Massari F, Di Nunno V, Conti A, Cimadamore A, Scarpelli M, Montironi R, Cheng L, Battelli N, Lopez-Beltran A. Immunotherapy in renal cell carcinoma: latest evidence and clinical implications. Drugs Context. 2018;7:212528.

25. Motzer RJ, Tannir NM, McDermott DF, Arén Frontera O, Melichar B, Choueiri TK, Plimack ER, Barthélémy P, Porta C, George S, et al. Nivolumab plus Ipilimumab versus Sunitinib in advanced renal-cell carcinoma. N Engl J Med. 2018;378(14):1277-90.

26. Chevrier S, Levine JH, Zanotelli VRT, Silina K, Schulz D, Bacac M, Ries CH, Ailles L, Jewett MAS, Moch H, et al. An Immune Atlas of Clear Cell Renal Cell Carcinoma. Cell. 2017:169(4):736-749.e718.

27. Gedye CA, Hussain A, Paterson J, Smrke A, Saini H, Sirskyj D, Pereira K, Lobo $\mathrm{N}$, Stewart J, Go C, et al. Cell surface profiling using high-throughput flow Cytometry: a platform for biomarker discovery and analysis of cellular heterogeneity. PLoS One. 2014;9(8):e105602.

28. The Cancer Genome Atlas Research N. Comprehensive molecular characterization of clear cell renal cell carcinoma. Nature. 2013; 499(7456):43-9.

29. de Hoon MJ, Imoto S, Nolan J, Miyano S. Open source clustering software. Bioinformatics. 2004:20(9):1453-4.

30. Picarda E, Ohaegbulam KC, Zang X. Molecular pathways: targeting B7-H3 (CD276) for human Cancer immunotherapy. Clin Cancer Res. 2016;22(14): 3425-31.

31. Goodpaster T, Legesse-Miller A, Hameed MR, Aisner SC, Randolph-Habecker J, Coller HA. An immunohistochemical method for identifying fibroblasts in formalin-fixed, paraffin-embedded tissue. J Histochem Cytochem. 2008;56(4): 347-58.

32. Skinnider BF, Folpe AL, Hennigar RA, Lim SD, Cohen C, Tamboli P, Young A, de Peralta-Venturina M, Amin MB. Distribution of cytokeratins and vimentin 
in adult renal neoplasms and normal renal tissue: potential utility of a cytokeratin antibody panel in the differential diagnosis of renal tumors. Am J Surg Pathol. 2005;29(6):747-54.

33. Waldherr R, Schwechheimer K. Co-expression of cytokeratin and vimentin intermediate-sized filaments in renal cell carcinomas. Virchows Archiv A. 1985;408(1):15-27.

34. Satelli A, Li S. Vimentin in cancer and its potential as a molecular target for cancer therapy. Cell Mol Life Sci. 2011;68(18):3033-46.

35. Mackay B, Ordonez NG, Khoursand J, Bennington JL. The ultrastructure and immunocytochemistry of renal cell carcinoma. Ultrastruct Pathol. 1987;11(56):483-502.

36. Yu W, Wang Y, Jiang Y, Zhang W, Li Y. Distinct immunophenotypes and prognostic factors in renal cell carcinoma with sarcomatoid differentiation: a systematic study of 19 immunohistochemical markers in 42 cases. BMC Cancer. 2017:17(1):293

37. Zolota V, Tsamandas AC, Melachrinou M, Batistatou A, Scopa C. Expression of CD44 protein in renal cell carcinomas: association with p53 expression. Urol Oncol. 2002;7(1):13-7.

38. Noroozinia F, Fahmideh A, Yekta Z, Rouhrazi H, Rasmi Y. Expression of CD44 and P53 in renal cell carcinoma: association with tumor subtypes. Saudi J Kidney Dis Transpl. 2014;25(1):79.

39. Bi M, Zhao S, Said JW, Merino MJ, Adeniran AJ, Xie Z, Nawaf CB, Choi J, Belldegrun AS, Pantuck AJ, et al. Genomic characterization of sarcomatoid transformation in clear cell renal cell carcinoma. Proc Natl Acad Sci. 2016; 113(8):2170-5.

40. Joseph RW, Millis SZ, Carballido EM, Bryant D, Gatalica Z, Reddy S, Bryce AH, Vogelzang NJ, Stanton ML, Castle EP, et al. PD-1 and PD-L1 expression in renal cell carcinoma with Sarcomatoid differentiation. Cancer Immunol Res. 2015;3(12):1303-7.

\section{Publisher's Note}

Springer Nature remains neutral with regard to jurisdictional claims in published maps and institutional affiliations.

Ready to submit your research? Choose BMC and benefit from:

- fast, convenient online submission

- thorough peer review by experienced researchers in your field

- rapid publication on acceptance

- support for research data, including large and complex data types

- gold Open Access which fosters wider collaboration and increased citations

- maximum visibility for your research: over $100 \mathrm{M}$ website views per year

At $\mathrm{BMC}$, research is always in progress.

Learn more biomedcentral.com/submissions 